\title{
Linear and Angular Issues in Perspective Artillery Fire Control System
}

\author{
Martin Blaha ${ }^{1, *}$, Karel Šilinger ${ }^{1}$, and Ladislav Potužák ${ }^{1}$ \\ ${ }^{1}$ UNIVERZITY OF DEFENCE (www.unob.cz), Faculty of Military Leadership, Department of Fire Support, Kounicova 65, Brno, \\ Czech Republic
}

\begin{abstract}
The Czech Republic, as a member of international organizations (NATO, EU, UNO), with respect to current global security neighborhood, employs the units of the army both at its own state territory and outside the Czech Republic, in multinational forces operations. The article focuses on Linear and Angular issues in perspective Artillery Fire Control System called PVNPG-14M. The issue of automated command, control, and information systems is of high importance in the solving of asymmetrical operations tasks today and in the upcoming future. The authors define appropriate Linear and Angular variables for common use by soldiers of the Army of the Czech Republic. Final assessment of the particular issues is determined by analysis. The The article contains theoretical justification and establishes a practical rule for use.
\end{abstract}

\section{Introduction}

The Field Artillery of the Czech Republic is an organic part of ground forces and at the same time one of the main medium of firing troops. Arty guns provide artillery support to mechanized units by firing, especially from covered firing positions.

Its main task is to eliminate the enemy's targets by effective artillery firing, which greatly reduces the loss of their own forces and equipment. When attacking their own Artillery gun systems, the artillery is able to fire also by direct firing on enemy combat vehicles. [15]

Efficiency of fire is achieved with high precision and surprise of fire. The premise of the surprise of the fire is also its quick start. To quickly launch a fire, it is necessary to quickly find the targets and to quickly determine the default values and firing elements. In order to quickly determine the starting values, distances, lengths and angles, a partial rule is used in practice to determine the necessary data with the required minimum accuracy. The use of a piece rule is known and commonly used in practice in both artillery and mechanized units. However, it is necessary for military professionals to know the nature and limits of use.

There is no standardized mile rule in the NATO armies (the circle consists of 6000 segments), but the others possibilities could be the circle is 6400 segments or 6300 . That is why, with the gradual transition to the mile standard of optical protractors, artillery guns, etc., the military professionals should know the essence, the practical use and the limits of the application of the mille rule, which were not used in the ACR until now. That's why authors decided to work on the basis of the issue to explain relatively simple issues on the subject and set the new limits for use.

\subsection{Short history and current state of the solved problem}

The practical application of the mile rule was already known in the Artillery of the First-Republic Czechoslovak Army. At that time, however, the circle was divided into 6400 angular units - segments. No fine-tuning corrections were used when using the mile rule. In the postwar Czechoslovak army, the circle was divided into 6000 angular units - segments, according to the Soviet pattern. [3] [16]

All artillery weapons and artillery reconnaissance means, in particular their protractor scale, resulted from this distribution. After the accession of the Czech Republic to NATO (12 March, 1999), the NATO standardization agreement is gradually being adopted, including the transition to the distribution of the circle to 6400 angular units. It is clear that for quite a long time before the takeover of new guns, mortars and artillery equipment the origin angular unit (6000 segments) and therefore the mile rule will be used. [14]

At present, modernization of artillery compass (buzola) is underway with a new mile distributions, which means that adjusting angle value on the cannons will be necessary to carry out with conversion. [15]

Also, personal observations of instruments, binoculars D-6, D-7 and EDF equipped with team and higher commanders (artillery and mechanized) have focal points with a crosshair, with five segments distributions both horizontally and vertically. D-6 and D-7 binoculars, which have already been removed from

\footnotetext{
* Corresponding author: martin.blaha@unob.cz
} 
the official equipment, can measure up to 140 mils in both the horizontal and vertical planes. EDF binoculars can measure only 60 mils, which is a drawback. [16]

In the rules of shooting and in other regulations, from the 1st Republic to the present, there is a sporadic mention of the mile rule (6000), and there is no mention of the mile rule (6400). Occasionally, the text rule is discussed in textbooks and scripts, but this documents have been cancelled many years ago. The practical application of the mile rule is set out in the "Rules of Artillery Fire and Fire Control", scheduled to be issued this year.

\section{Artillery angular rate}

Arithmetic operations are often used to solve tasks in ground artillery firing where angular or longitudinal values are required.

Generally used angular units - degrees, minutes, and seconds are not suitable for battlefield calculations, as it is often necessary to recalculate degrees to minutes, etc. Therefore, in artillery, a particular angular rate - dílec (dc; 6000) or mil (6400 (Figure 1, 2) is used.

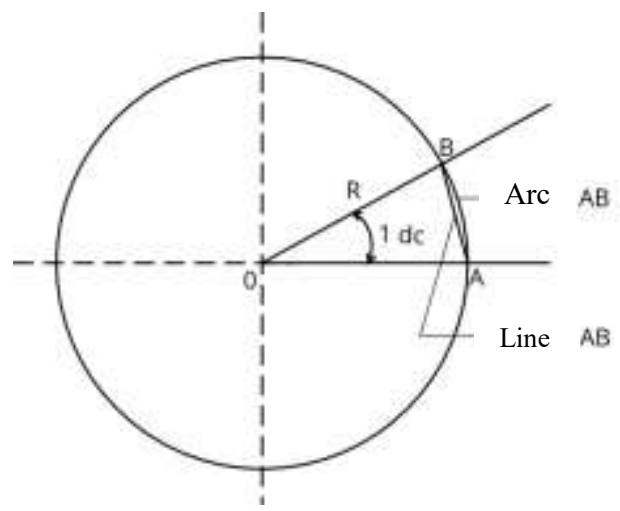

Fig. 1. Representation of dc

The Dílec (dc) is defined as a centre angle which is below the line (arc) of approximately $1 \mathrm{~m}(1.05 \mathrm{~m})$ long at a distance of $1 \mathrm{~km}$. The Dílec corresponds to the $1 / 6000$ length of the arc of the circle. The whole circle is therefore divided into 6000 segments (60-00).

The 1-meter $\mathrm{AB}$ line is in this case a chord with a circle and corresponds to the $\mathrm{AB}$ curve (Figure 1), which is somewhat longer.

The length of the arc AB:

$$
\widehat{\mathrm{AB}}=\frac{2 \pi R}{6000} \cdot \alpha,
$$

because

$$
a=1 d c
$$

$$
\widehat{\mathrm{AB}}=\frac{2 \pi R}{6000}=\frac{6,28}{6000} \cdot \mathrm{R}=\frac{1}{955} \mathrm{R}=0,0010472 \mathrm{R}
$$

after putting $\quad \mathrm{R}=1000 \mathrm{~m}$,

$$
\widehat{\mathrm{AB}} \doteq 1,0472 m=1,05 m
$$

The difference between the length of the arc $\mathrm{AB}$ and the line $\mathrm{AB}$ is about $0.05 \mathrm{~m}$, which corresponds to $5 \%$.

Mil is defined as the centre angle which is below the line (arc) of approximately $10 \mathrm{~cm}$ at a distance of $100 \mathrm{~m}$. For artillery practice, the definition is more convenient: mil is the centre angle which is below a line (arch) of approximately $1 \mathrm{~m}(0.98 \mathrm{~m})$ at a distance of $1 \mathrm{~km}$. Mil corresponds to 1/6400 arc length of the circle. The whole circle is therefore divided into 6400 miles (64-00). The 1-meter AB line is in this case a part of the tangent to the circle and corresponds to the $\mathrm{CD}$ curve, which is somewhat shorter (Figure 2).

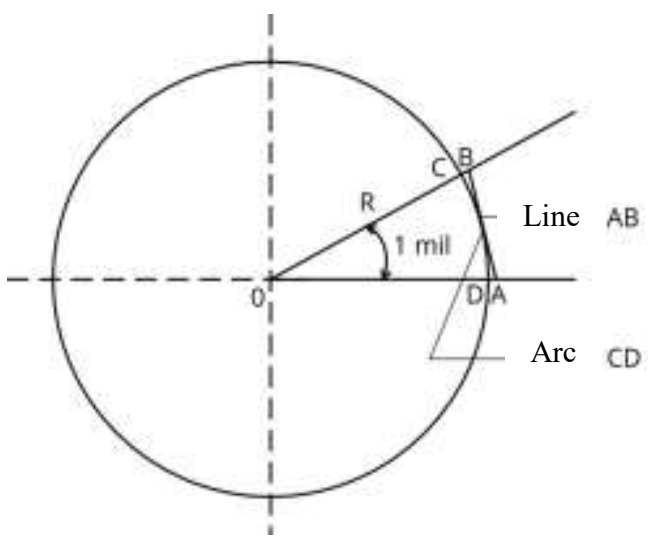

Fig. 2. Representation of mil

The length of the arc CD:

$$
\overparen{C D}=\frac{2 \pi R}{6400} \cdot \alpha,
$$

$$
\begin{aligned}
& \text { because } \quad \alpha=1 \mathrm{mil} \text {, } \\
& \overparen{C D}=\frac{2 \pi R}{6400}=\frac{6,28}{6400} \cdot R=\frac{1}{1019} \cdot R=0,0009812 R \\
& \text { after putting } \quad \mathrm{R}=1000 \mathrm{~m} \text {, } \\
& \overparen{C D}=0,9812 m=0,98 m
\end{aligned}
$$

The difference between the length of the $\mathrm{CD}$ arc and the line $\mathrm{AB}$ is about $0.02 \mathrm{~m}$ corresponding to $2 \%$.

Thus, the approximate length of the arc corresponding to one segment (mil) is equal to $1 / 1000$ of the radius of the given circle.

The conversion formula from miles to dilec is $15 / 16(6000 / 6400)$ and from dilec to miles $16 / 15$.

To simplify the oral transmission of values, and also to the construction of scales of various, especially artillery devices, hundreds of dilec (miles) are separated from tens and units. This method of forwarding is also used when writing angles. 


\section{Relationship between Linear and Angular values}

Let us denote in an isosceles triangle MON a distance "l" between two points $\mathrm{M}, \mathrm{N}$ (centre $(\mathrm{S})$ ) equally distant the angle between the directions to these points $\alpha$, the distance from the cannon (observer) to these points $d$ and $\mathrm{d}_{1}$ distance of the point $\mathrm{S}$ from point 0 (Figure 3 ).

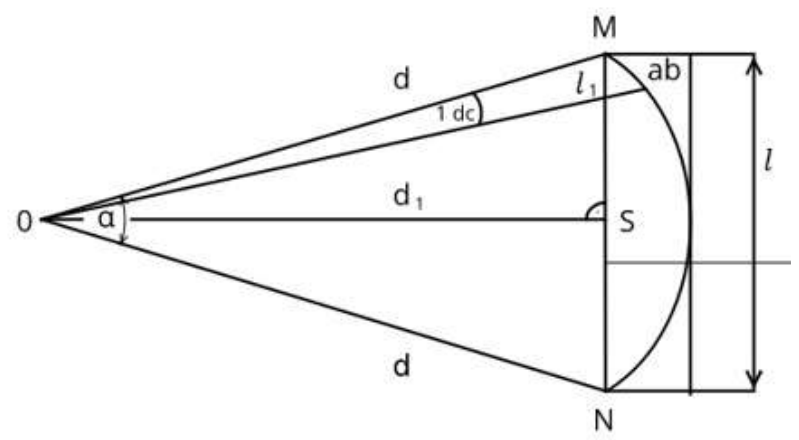

Fig. 3. Relationship between Linear and Angular presentation of $\mathrm{dc}$

If we use the known trigonometric functions to solve a rectangular triangle, we will get it:

$$
l=d \cdot 2 \cdot \sin \frac{\alpha}{2}=d_{1} \cdot 2 \cdot \operatorname{tg} \frac{\alpha}{2}
$$

If the triangle MON is rectangular (Fig. 4), its side MO will be perpendicular to MN (this way we can think in practice at small angles $\alpha$ ), we can express the distance 1:

$$
l=d \cdot \sin \alpha\left(=d_{1} \times \operatorname{tg} \alpha\right)
$$

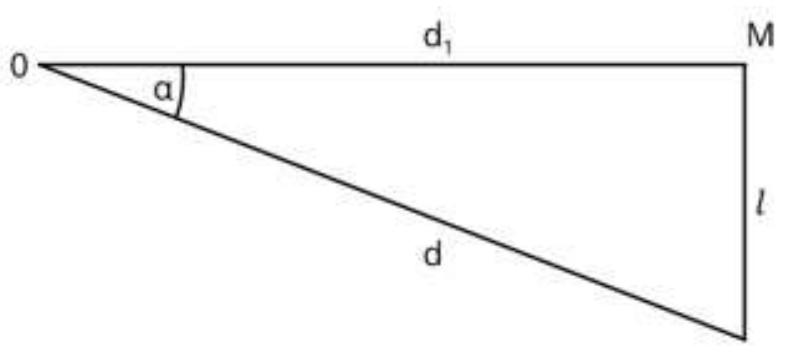

Fig. 4. Determination of length 1 from rectangular triangle

Formulas (3), (4) are not practical in practice because their use requires knowledge of trigonometric functions. [3]

Determine the dependence of the length "l" on the distance "d" for an angle of $1 \mathrm{dc}$. From the table (by determining) the values of the trigonometric functions we get:

$\sin 0-01=\operatorname{tg} 0-01=2 \sin \frac{0-01}{2}=2 \operatorname{tg} \frac{0-01}{2}=0,0010472$

which also follows from the formula (2).

We know that the length of the arc $A B$, corresponding to one dilec, is determined by the formula $l_{1}=0,0010472 \mathrm{R} \doteq 0,001 \mathrm{R}(2)$ or if the received mark (Fig. 3) to the nearest thousandths

$$
l_{1}=0,001 \mathrm{~d}
$$

Since the angle between the equally distant objects will be one times larger than the part, the length of the arc $\mathrm{MN}$ will be a greater than the arc, so:

$$
\begin{aligned}
& \mathrm{MN}=l_{1} \cdot \alpha \\
& \mathrm{MN}=0,001 \mathrm{~d} \cdot \alpha \\
& \mathrm{MN}=l=0,001 \mathrm{~d} \cdot \alpha
\end{aligned}
$$

Formula (11) has a very wide application in solving simple practical tasks. Allows you to specify the third value according to two known values:

1) If the angle between two equally distant points (objects) and the distance to them is known, it is possible to determine the distance between these points (eg the width of the target)

$$
l=\alpha \cdot \frac{d}{1000}=\alpha \cdot 0,001 d
$$

2) If the distance between the two points is known and the distance to them, it is possible to determine the magnitude of the angle $\alpha$ in the dilec between the directions to these points:

$$
\alpha=\frac{1000-l}{d}=\frac{l}{0,001 d}
$$

3) If the distance between the two points is known and the angle in the dilec between these points is known, it is possible to determine the distance to them:

$$
\begin{aligned}
& \mathrm{d}=\frac{1000-l}{\alpha} \\
& 0,001 \mathrm{~d}=\frac{l}{\alpha}
\end{aligned}
$$
rule.

The aggregate use of these formulas is called a mills

Formula (5) and its various shapes allow you to solve simple practical tasks quickly and on the go. However, these formulas are approximate and the errors in their use are the larger the larger the angle $\alpha$.

To elucidate the essence of the assumption that forms the basis of formula (5), compare the right parts of formulas (4) and (5):

$$
\frac{d \cdot \alpha}{1000}=d \cdot \sin \alpha
$$

From (16) we get : $\alpha \doteq 1000 \times \sin \alpha$ 
The accuracy of the calculations using formula (11) therefore depends on the accuracy of equations (16) and (17) and these again at the angle $\alpha$. Table 1 show errors $(\Delta)$ of equations (16) and (17) calculated according to the formulas:

$$
\begin{aligned}
& \Delta^{\prime}=\alpha-1000 \times \sin \alpha \\
& \Delta^{\prime \prime}=\alpha-1000 \cdot \operatorname{tg} \alpha
\end{aligned}
$$

Relative errors $(\delta)$ in determining the length "l" calculated by the formulas:

$$
\begin{aligned}
& \delta^{\prime}=\frac{\frac{d \times \alpha}{1000}-d \cdot \sin \alpha}{d \times \sin \alpha}=\frac{\alpha-1000 \times \sin \alpha}{1000 \times \sin \alpha}=\frac{\Delta^{\prime}}{1000 \times \sin \alpha} \\
& \delta^{\prime \prime}=\frac{\frac{d \cdot \alpha}{1000}-d \times \operatorname{tg} \alpha}{d \times \operatorname{tg} \alpha}=\frac{\alpha-1000 \times \operatorname{tg} \alpha}{1000 \times \operatorname{tg} \alpha}=\frac{\Delta^{\prime \prime}}{1000 \cdot \operatorname{tg} \alpha}
\end{aligned}
$$

Table 1. Equation errors and relative errors of determination of length " $l$ " if the angles $\alpha$ are in the dilec.

\begin{tabular}{|c|c|c|c|c|c|c|}
\hline \multirow{2}{*}{$d(d c)$} & \multicolumn{3}{|c|}{$d \cdot \sin \alpha$} & \multicolumn{3}{c|}{$d \cdot \operatorname{tg} \alpha$} \\
\cline { 2 - 7 } & $1000 \cdot \sin \alpha$ & $\Delta^{\prime}(\mathrm{dc})$ & $\delta^{\prime}(\%)$ & $1000 \cdot \operatorname{tg} \alpha$ & $\Delta^{\prime \prime}(\mathrm{dc})$ & $\delta^{\prime \prime}(\%)$ \\
\hline $0-01$ & 1,047 & $-0,047$ & $-4,5$ & 1,047 & $-0,047$ & $-4,5$ \\
\hline $0-10$ & 10,47 & $-0,47$ & $-4,5$ & 10,47 & $-0,47$ & $-4,5$ \\
\hline $0-20$ & 20,94 & $-0,94$ & $-4,5$ & 20,95 & $-0,95$ & $-4,5$ \\
\hline $0-50$ & 52,34 & $-2,34$ & $-4,5$ & 52,4 & $-2,4$ & $-4,6$ \\
\hline $1-00$ & 104,5 & $-4,5$ & $-4,3$ & 105,1 & $-5,1$ & $-4,9$ \\
\hline $2-00$ & 207,9 & $-7,9$ & $-3,8$ & 212,6 & $-12,6$ & $-5,9$ \\
\hline $3-00$ & 309,0 & $-9,0$ & $-2,9$ & 324,9 & $-24,9$ & $-7,7$ \\
\hline $4-00$ & 406,7 & $-6,7$ & $-1,6$ & 445,2 & $-45,2$ & $-10,2$ \\
\hline $5-00$ & 500,0 & 0 & 0 & 577,4 & $-77,4$ & $-13,4$ \\
\hline
\end{tabular}

From the results shown in the table the following conclusions are drawn:

1) If the exact value of length " 1 " is determined by $\sin \alpha$, the distance (length) " $\mathrm{d}$ " is the rectangle of the rectangular triangle, then the error $\Delta^{\prime}$ of equation (17) has a negative value and at angles $\alpha$ from 0 to $300 \mathrm{dc}$ its absolute value is increased to $9 \mathrm{dc}$, when angles $\alpha$ is from 300 to $500 \mathrm{dc}$ its decreases to zero. The relative error $\left(\delta^{\prime}\right)$ of determining the length "l" according to formula (11) decreases from $4.5 \%$ to zero. [15]

2) If the exact value of length "l" is determined by $\operatorname{tg} \alpha$, the distance (length) " $\mathrm{d}$ " is a vertical rectangular triangle, then the error $\left(\Delta^{\prime \prime}\right)$ of the equation increases to its absolute value to $77.4 \mathrm{dc}$ and the relative error ( $\left.\delta^{\prime \prime}\right)$ increases from $4.5 \%$ to $13.4 \%$. For practice, the accuracy of the calculations according to formula (11) and derived formulas is achievable in case of errors $\Delta$ not exceeding 1 dilec, which is achieved at angles $\alpha$ from 0 to $20 \mathrm{dc}$.

3) Irrespective of whether the distance (length) " $d$ " is a displacement or a regular triangle, the relative error $(\delta)$ at angles from 0 to $100 \mathrm{dc}$ is approximately the same and equals $5 \%$. Generally, this error results from the fact that one dilec is taken as $1 / 1000$ " $\mathrm{d}$ " and not $1 / 955$ "d" (the arch is replaced with the chord). Excluding this systematic error by refining the results of the $5 \%$ correction calculation thus permits to use formula (11) and derived formulas at angles $\alpha$ to $100 \mathrm{dc}$, as this correction is also a rounded value. By analyzing these formulas, we arrive at the conclusion that the calculated length "l" should be increased by $5 \%$ (multiply the result by 1,05 ) and the calculated angle $\alpha$ and the distance "d" should be reduced by $5 \%$ (multiply the result by 0,95 ) angle $\alpha$ in the dilce.

\section{Conclusions}

The mile rule will also be used in the future to quickly and accurately determine the values. With the gradual reassembly of cannons and mortars of standard NATO caliber, replacement and upgrading of devices where the basic angular unit is $1 \mathrm{mil}$.

After equipping artillery team leaders with the abovementioned focal point telescopes made with mile grading, the mile rule will be used. Mile rule with $5 \%$ correction allows for the use of formulas to calculate values at angles up to 100 dilec (miles), which is in fact fully sufficient. [15]

Calculation of $5 \%$ correction is required for the mile rule at angles above 10 dilec.

It is necessary for military professionals not only to safely control the use of formulas, but also to know the nature and conditions of the application of rule.

\section{Acknowledgment}

The work was supported by the Ministry of Education, Youth and Sports of the Czech Republic, project No. SV16-FVL-K107-ŠIL

\section{References}

1. BLAHA, M., SOBARŇA, M. Principles of the Army of the Czech Republic Reconnaissance and Fire Units Combat using. In The 15th International Conference „The Knowledge-Based Organization“. Sibiu (Romania): Nicolae Balcescu Land Forces Academy, 2009, pp. 17-25.

2. BLAHA, M., BRABCOVÁ, K. Decision-Making by Effective C2I system. In The 7th International Conference on Information Warfare and Security. Seattle (USA): Academic Publishing Limited, 2012, pp. 44-51. ISBN 978-1-908272-29-4.

3. Joint Forces Command, Training. Shooting Rules and ground artillery fire control (gun, platoon, 
battery compartment). Pub-74-14-1. Prague: 2007. $256 \mathrm{p}$.

4. BLAHA, M., SOBARŇA, M. Some develop aspects of perspective Fire Support Control System in Czech Army conditions. In The 6th WSEAS International Conference on Dynamical Systems and Control. Sousse (Tunisia): University of Sfax, 2010, pp. $179-183$.

5. AD-6.1 Doctrine of Communication and Information systems. Praha: MO CR, 2003.

6. AAP-6 NATO Glossary of Terms and Definitions (english and french). 2009.

7. BLAHA, M., BRABCOVÁ, K. Communication environment in the perspective Automated Artillery Fire Support Control System. In The 10th WSEAS International Conference on APPLIED INFORMATICS AND COMMUNICATIONS (AIC '10). Taipei, 2010. pp. 236-240. ISBN 978-960-474216-5.

8. BLAHA, Martin, POTUŽÁK, Ladislav. Decisions in the perspective Automated Artillery Fire Support. In: Recent Researches in Applied Informatics \& Remote Sensing. Penang: Wseas Press, 2011, p. 8791. ISBN 978-1-61804-039-8.

9. NATO Standardization Agency. AArtyP-1 (A) Artillery Procedures. Brussels, Belgium, 2004. $102 \mathrm{p}$.

10. NATO Standardization Agency. AArtyP-5 (A) NATO Indirect Fire Systems Tactical Doctrine. Brussels, Belgium, 2013. 121 p.

11. DUBEC, Radek; HRŮZA, Petr. Military Concept of Modularity. Croatian Journal of Education, 2012, vol. 14, no. Spec.Ed. 1, p. 35-41. ISSN 1848-5189.

12. MAJEK, V., SLOUF, V. Operations with fuzzy numbers in the task divided targets. In ICMT 2015 International Conference on Military Technologies 2015, pp. 641-645.

13. MAZAL, J., STODOLA, P., at al. Math modelling of the basic defensive activities. In: Proceedings of the International Conference on Applied Physics, Simulation and Computers (APSAC 2015). Vienna, Austria: Institute for Natural Sciences and Engineering (INASE), 2015, p. 116-120. ISSN 1790-5109. ISBN 978-1-61804-286-6.

14. ŠILINGER, K., BRABCOVÁ, K., POTUŽÁK, L. Assessment of Possibility to Conduct Fire for Effect without Adjust Fire according to Observational Distance of a Target in Artillery Automated Fire Control Systems. In: Recent Advances in Systems, Control and Informatics. Venice: EUROPMENT, 2013 , p. 335-340. ISSN 1790-5117. ISBN 978-161804-206-4.

15. BLAHA, M., ŠILINGER, K. Setting a Method of Determination of "Fire for Effect" Firing Data and Conversion of the METCM into the METEO-11. International Journal of Circuits, Systems and Signal Processing, 2015, no. 9, 2015, p. 306-3013. ISSN 1998-4464.
16. BLAHA, Martin; ŠILINGER, Karel; POTUŽÁK, Ladislav; P̌̌IKRYL, Bohuslav. Perspective method for determination of fire for effect in tactical and technical control of artillery units. In: ICINCO 2016 Proceedings of the 13th International Conference on Informatics in Control, Automation and Robotics. Portugalsko: SCITEPRESS, 2016, p. 249-254. ISBN 978-989-758-198-4.

17. BLAHA, Martin; ŠILINGER, Karel; POTUŽÁK, Ladislav. Data Binding Issue in Fire Control Application for Technical Control of Artillery Fire. In: The 21st World Multi-Conference on Systemics, Cybernetics and Informatics. Orlando, Florida: International Institute of Informatics and Systemics, 2017, p. 4-8. ISBN 9781941763582.

18. ŠILINGER, Karel; BLAHA, Martin. Conversions of METB3 Meteorological Messages into the METEO11 Format. In: 2017 International Conference on Military Technologies (ICMT). Brno: University of Defence, 2017, p. 278-284. ISBN 9781-5386-1988-9.

19. ŠILINGER, K., IVAN, J. and LADISLAV, P., 2017. Composition of the METEO11 meteorological message according to abstract of a measured meteorological data, ICMT 2017 - 6th International Conference on Military Technologies 2017, pp. 194199.

20. ŠILINGER, K., BLAHA, M. and PRIKRYL, B., 2017. Alternative compilation of the METEO11 meteorological message, WMSCI 2017 - 21st World Multi-Conference on Systemics, Cybernetics and Informatics, Proceedings 2017, pp. 80-85.

21. STODOLA, Petr; MAZAL, Jan. Model of Optimal Cooperative Reconnaissance and its Solution using Metaheuristic Methods. Defence Science Journal, 2017, vol. 67, no. 5, p. 529-535. ISSN 0011-748X.

22. STODOLA, Petr. Improvement in the Model of Cooperative Aerial Reconnaissance Used in the Tactical Decision Support System. The Journal of Defense Modeling and Simulation, 2017, vol. 14 , no. 4, p. 483-492. ISSN 1548-5129. 